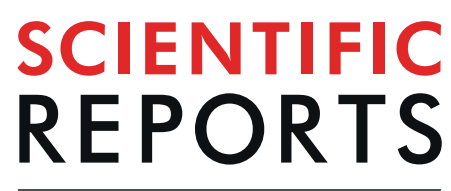

natureresearch

\title{
Printable Highly Stable and Superfast Humidity Sensor Based on Two Dimensional Molybdenum Diselenide
}

\author{
Muhammad Awais ${ }^{1,3}$, Muhammad Umair Khan ${ }^{2,3}$, Arshad Hassan $^{1 *}$, Jinho Bae $^{2 *} \&$ \\ Tahseen Elahi Chattha ${ }^{1}$
}

Transition metal dichalcogenides (TMDCs) are promising materials for sensing applications, due to their exceptional high performance in nano-electronics. Inherentely, the chemical and thermal responses of TMDCs are highly stable, hence, they pave way for real time sensor applications. This article proposes inceptively a stable and superfast humidity sensor using two-dimensional (2D) Molybdenum diselenide $\left(\mathrm{MoSe}_{2}\right)$ through printed technlogies. The 2D MoSe $e_{2}$ ink is synthesized through wet grinding to achieve few-layered nano-flakes. Inter digital electrodes (IDEs) are fabricated via screen-printing on Polyethylene terephthalate (PET) substrate and thin film of $\mathrm{MoSe}_{2}$ nano-flakes is fabricated through spin coating. The impedance and capacitance response are recorded at $1 \mathrm{kHz}$ between temperature levels ranging from $20-30^{\circ} \mathrm{C}$. The impedance and capacitance hysteresis results are recorded $<1.98 \%$ and $<2.36 \%$, respectively, ensuring very good repeatability during humidification and dehumidification. The stability of impedance and capacitance response are recorded with maximum error rate of $\sim 0.162 \%$ and $\sim 0.183 \%$, respectively. The proposed sensor shows fast impedance response time $\left(T_{\text {res }}\right)$ of $\sim 0.96 \mathrm{~s}$, and recovery time $\left(T_{\text {rec }}\right)$ of $\sim 1.03 \mathrm{~s}$, which has $T_{\text {res }}$ of $\sim 1.87 \mathrm{~s}$, and $T_{\text {rec }}$ of $\sim$ $2.13 \mathrm{~s}$ for capacitance. It is aimed to develop a high performance and stable humidity sensor for various monitoring applications.

Two-dimensional (2D) materials exhibit exceptional physical properties when charge and heat are restricted to a planar layer ${ }^{1}$. Moreover, higher surface to volume ratio of $2 \mathrm{D}$ materials favor easy fabrication of sensing layers and smaller size of the electronic devices ${ }^{2}$. Discovery of mechanically exfoliated graphene in $2004^{3}$, offered new ground to nanotechnology having advantages like high carrier mobility ${ }^{4}$, transparency, and flexibility ${ }^{5}$. Carbon atoms are arranged in a honeycomb lattice structure in $2 \mathrm{D}$ graphene ${ }^{1}$. However, the approximate zero band gap of the graphene obstructs its utility in electronic sensing devices owing to low on/off ratio. Various 2D materials have been reported as humidity sensors, however, these have long response and recovery times equivalent to $\approx 10 \sec ^{6-10}$. which restricts their usage as humidity sensors in real time monitoring and health services ${ }^{11}$. In recent years, active research is under consideration for development of layered structures of transition metal dichalcogenides (TMDCs), as a low-cost, fast, directly printable 2D semiconductor material. Two-dimensional TMDCs, too, share a high carrier mobility of $500 \mathrm{~cm}^{2} / \mathrm{Vs}^{12}$, and are being utilized in gas ${ }^{13}$, temperature ${ }^{14}$, electronic $^{15-22}$, and optoelectronics ${ }^{23-27}$ sensing applications because of their exceptional properties ${ }^{23,28}$. General formula for TMDC is given as $\mathrm{MX}_{2}$ where $\mathrm{M}$ can be $\mathrm{Sn}, \mathrm{W}, \mathrm{Mo}, \mathrm{V}$ etc., while $\mathrm{X}$ can be $\mathrm{S}, \mathrm{Se}$, Te etc.

In this work, Molybdenum diselenide $\left(\mathrm{MoSe}_{2}\right)$ is chosen due to its exceptional humidity sensing capabilities $^{12}$, and its higher electrical conductivity. Molybdenum diselenide offers unchanged wear rate under humid conditions even at high temperatures of $350^{\circ} \mathrm{C}^{29}$. The Electron Affinity (EA) of 4.42 and Work Function $(\varphi)$ of 5.20 were calculated for $\mathrm{MoSe}_{2}$, respectively ${ }^{30,31}$. These results emphasize that electron extraction is much easier for $\mathrm{MoSe}_{2}$ as compare to other members of the same family ${ }^{30}$. $\mathrm{MoSe}_{2}$ has a higher tendency to donate an electron and interact with hydrogen molecules. $\mathrm{MoSe}_{2}$ presents higher electrical conductivity of $10^{-3} \mathrm{Sm}^{-1}$ due to

\footnotetext{
${ }^{1}$ National University of Computer \& Emerging Sciences (NUCES), Islamabad, Pakistan. ${ }^{2}$ Department of Ocean System Engineering, Jeju National University, 102 Jejudaehakro, Jeju, 63243, Republic of Korea. ${ }^{3}$ These authors contributed equally: Muhammad Awais and Muhammad Umair Khan. *email: arshad.hassan@nu.edu.pk; baejh@ jejunu.ac.kr
} 
Selenium's metallic nature ${ }^{32}$. MoSe $\mathrm{M}_{2}$ has a density of $6.96 \mathrm{~g} / \mathrm{cm}^{3}$, with a layer thickness of $\approx 6-7 \AA$, and $\approx 2.49 \AA$ and $\approx 3.29 \AA \mathrm{Mo}-\mathrm{Se}$ and Se-Se bond lengths, respectively ${ }^{33-35}$. Energy band gap of TMDCs is greater than 1.0 $\mathrm{eV}^{3}$, and greater than graphene and its variants. Single layer $\mathrm{MoSe}_{2}$ exhibits an energy band gap of $1.55 \mathrm{eV}^{36-38}$. Thus, TMDCs require lesser power for operation than the pervoskites which display a higher energy band gap ${ }^{39}$. $\mathrm{MoSe}_{2}$ is catalytically active in hydrogen adsorption ${ }^{30}$ with $100 \%$ Hydrogen interactions at edges, and it has a very low edge binding energy of $-13.1 \mathrm{meV} /$ f.u. Hydrogen binding energy for $\mathrm{Mo}-\mathrm{H}$ and Se-H bonds calculated is $-32.3 \mathrm{meV} / \mathrm{f}$.u, $-13.1 \mathrm{meV} / \mathrm{f}$.u respectively, for $\mathrm{MoSe}_{2}{ }^{30}$. This makes $\mathrm{MoSe}_{2}$ suitable for stable and superfast humidity sensing material.

In the present work, a humidity sensor based on synthesized nano-flakes of $\mathrm{MoSe}_{2}$ is demonstrated. The nano-flakes in the synthesized ink have the higher surface roughness contributing to excessive surface area, and utilizing these flakes gave superfast response $(\sim 0.96 \mathrm{~s})$ and recovery time $(\sim 1.03 \mathrm{~s})$. Fabrication of IDEs of the proposed sensor was performed, with screen-printing technique, while spin coating technique was utilized for printing $\mathrm{MoSe}_{2}$ sensing layer. Optimization of the sensor design was achieved by simulation of three sensors with IDEs spacing of $300 \mu \mathrm{m}, 200 \mu \mathrm{m}$, and $100 \mu \mathrm{m}$ for sensor 1, sensor 2, and sensor 3, respectively. Simulation results suggested that size and spacing of electrodes at $100 \mu \mathrm{m}$ gives the best performance in terms of lowest impedance and highest capacitance because it is desirable for detection in low RH and practical measurement perspective $^{40,41}$. These results were in accordance with the smaller width and smaller spacing criteria ${ }^{42}$. The screen-printing through mask, restricted the resolution of fabrication and optimization of the sensor at $100 \mu \mathrm{m}$ spacing and width of IDEs, hence the sensor was designed in COMSOL in accordance with the printing limitations as discussed in Section 2 of this paper and sizing optimization is discussed in Supplementary information file. In terms of stability, this work presents the temperature dependence of $\mathrm{MoSe}_{2}$ on different humidity levels. The presented $\mathrm{MoSe}_{2}$ based humidity sensor is suitable for a mass production as all fabrication steps are compatible with all printed electronic approaches.

\section{Materials and Methods}

Inter digitated electrodes design and fabrication. The Inter Digital Electrodes (IDEs) were fabricated using screen-printer Automax System Engineering AMX-1240M as shown in Fig. 1a. Initially, PET substrate was placed on printing platform, IDEs mask screen was fixed in screen-printer and screen-printing Silver (Ag) ink was placed on printing mask. The squeegee was used to spread ink on printing mask. After complete spreading of Ag ink on printing mask, IDEs were cured at $120^{\circ} \mathrm{C}$. Each electrode consisted of two parts, first a plate of measurement $20 \mathrm{~mm} \times 5 \mathrm{~mm}$ length and width respectively with a thickness of $10 \mu \mathrm{m}$, second the electrode fingers of $10 \mathrm{~mm} \times 100 \mu \mathrm{m}$ length and width, respectively, with a thickness of $10 \mu \mathrm{m}$. A constant finger spacing of $100 \mu \mathrm{m}$ was kept between IDEs. The overall size of sensor was $20 \mathrm{~mm} \times 22 \mathrm{~mm}$ with a spacer of $2 \mathrm{~mm}$ between positive and negative electrode ends. Fabricated IDEs are shown in Fig. 1b. In addition, the IDEs were designed in computer software platform COMSOL Multiphysics 5.3a to verify the practical results with simulated results as shown in Fig. 1c.

$\mathrm{MoSe}_{2}$ ink preparation. Molybdenum (IV) Selenide $\left(\mathrm{MoSe}_{2}\right) \sim 325$ mesh with $99.9 \%$ trace metals basis, N-Methyl-2-Pyrrolidone (NMP) were bought from Sigma Aldrich, South Korea. The screen-printing Ag ink TEC-PA-051LV with viscosity $155,000 \pm 15,000 \mathrm{cps}$, density $\sim 2.8 \pm 0.2 \mathrm{~g} / \mathrm{cm}^{3}$, and metal content $\sim 70 \pm 2 \mathrm{wt} \%$ was purchased from InkTec. The $100 \mu \mathrm{m}$ thick PET substrate was purchased from AgIC paper. MoSe $\mathrm{ink}_{\text {ink }}$ synthesized via wet grinding assisted co-solvent sonication followed by mechanical shaking, bath sonication, probe sonication and centrifugation a shown in Fig. S6 of Supplementary Information. $\mathrm{MoSe}_{2}$ ultra-fine powder was ground in mortar and pester for $8 \mathrm{~h}$ using NMP. After grinding, gel like mixture was placed on heater to dry at $110^{\circ} \mathrm{C}$ for $1 \mathrm{~h}$. The dried $7 \mathrm{mg} \mathrm{mL}^{-1} \mathrm{MoSe}_{2}$ powder was mixed in NMP and placed on magnetic stirrer for $24 \mathrm{~h}$ at $1,200 \mathrm{rpm}$. Further, $\mathrm{MoSe}_{2}$ solution was probe sonicated for $1 \mathrm{~h}$ with on pulse of $1 \mathrm{~s}$ and off pulse of $3 \mathrm{~s}$ at probe frequency $\sim 19.7 \mathrm{kHz}$ and bath sonicated for $30 \mathrm{~min}$. The $2 / 3$ portion of $\mathrm{MoSe}_{2}$ solution was centrifuged at $6,000 \mathrm{rpm}$ for $20 \mathrm{~min}$ and supernatant was obtained by decantation. The $\mathrm{MoSe}_{2}$ nano-flakes film was fabricated using spin coater at $300 \mathrm{rpm}$ for $10 \mathrm{~s} \mathrm{ramp}$ and $4,000 \mathrm{rpm}$ for $60 \mathrm{~s}$.

Characterization. The surface morphology of $\mathrm{MoSe}_{2}$ was analyzed with scanning electron microscope (SEM) Jeol JSM-7600F, and element determination was analyzed with energy dispersive X-ray (EDS) spectrometer. The 2D and 3D nano-profile of IDEs and $\mathrm{MoSe}_{2}$ were analyzed with NV-2000 Universal non-contact surface profiler. The Raman shift of $\mathrm{MoSe}_{2}$ nanoflakes are provided in Supplementary information. The 2D Nano-profile of IDEs is shown in Fig. 1d, which ensures that electrodes were correctly fabricated with screen-printer with surface roughness $\sim 2.55 \mu \mathrm{m}$. The 3D Nano profile of IDEs are shown in Fig. 1e, representing the average height of IDEs $\sim 9.68 \mu \mathrm{m}$. The surface morphology of $\mathrm{MoSe}_{2}$ nano-flakes was observed at $500 \mathrm{~nm}$ a shown in Fig. $2 \mathrm{a}$. The EDS spot profile of $\mathrm{MoSe}_{2}$ nano-flakes is shown in Fig. 2b, which confirms the presence of Mo and Se peaks with atomic percentage $33.1 \%$ and $66.9 \%$, respectively. The EDS mapped image of $\mathrm{MoSe}_{2}$ with magnification level of $500 \mathrm{~nm}$ as shown in Fig. 2c confirms the presence of Se L series as shown in Fig. 2d, and Mo L series in Fig. 2e. The $2 \mathrm{D}$ nano-profile of $\mathrm{MoSe}_{2}$ flaks is shown in Fig. $2 \mathrm{f}$, which confirms the active layer roughness $\sim 145.82 \mathrm{~nm}$. The average height profile of $\mathrm{MoSe}_{2}$ flaks $\sim 0.81 \mu \mathrm{m}$ is shown in Fig. $2 \mathrm{~g}$.

Conduction mechanism. The $\mathrm{MoSe}_{2}$ nano-flakes respond to humidity and dielectric constant of the film increases as compared to the dry film and ionic current flows through the sensor. With exposure of sensor to humidity and the hydroxyl ions, water molecules get absorbed into the thin film of $\mathrm{MoSe}_{2}$ and ionic conduction paths are formed between $\mathrm{MoSe}_{2}$ nano-flakes. This results in decrease of overall sheet resistance. Figure 3 shows random sized and randomly placed nano-flakes above the IDEs. Additionally, void spaces are created between the layers of $\mathrm{MoSe}_{2}$ nano-flakes, which not only increase the Molybdenum and Selenium edges for $\mathrm{H}$ 
(a) Spreading Ag ink on IDEs using squeegee
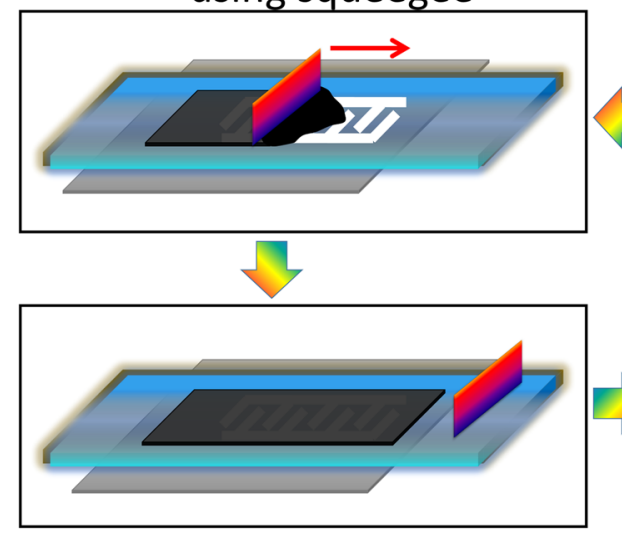

Ag ink is completely spread on Printing Mask

(b) Fabricated IDEs

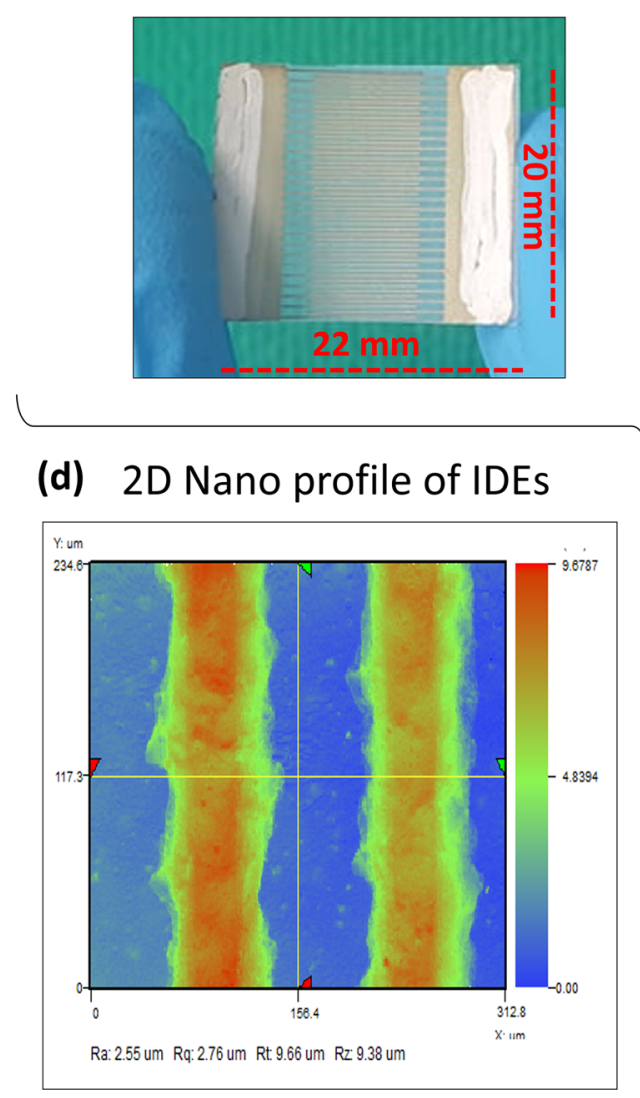

(d) 2D Nano profile of IDEs

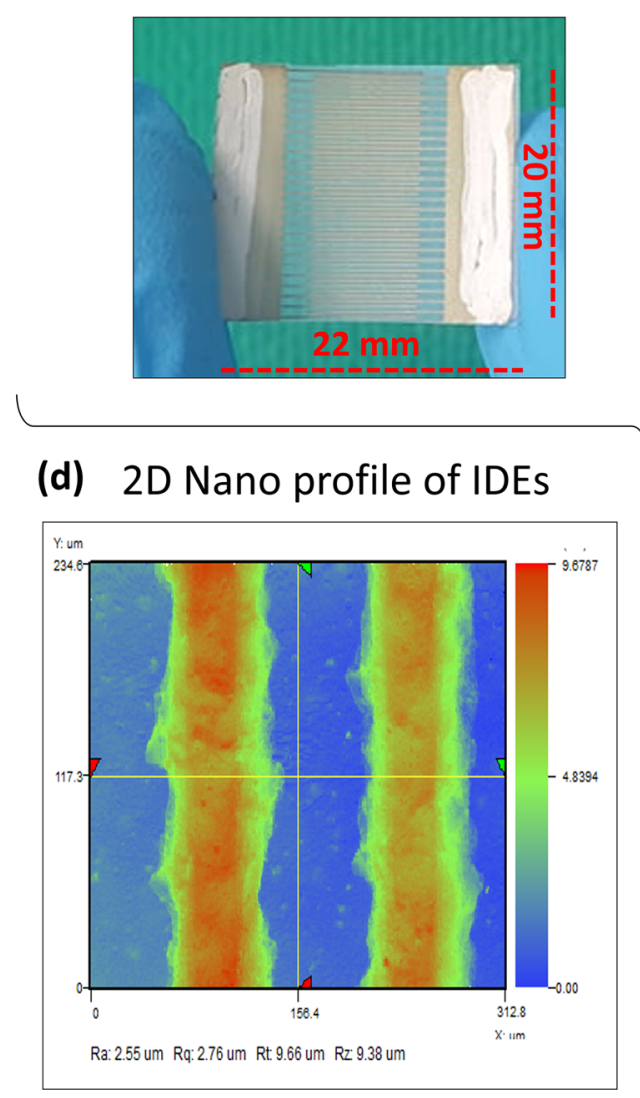

Screen Printing Setup
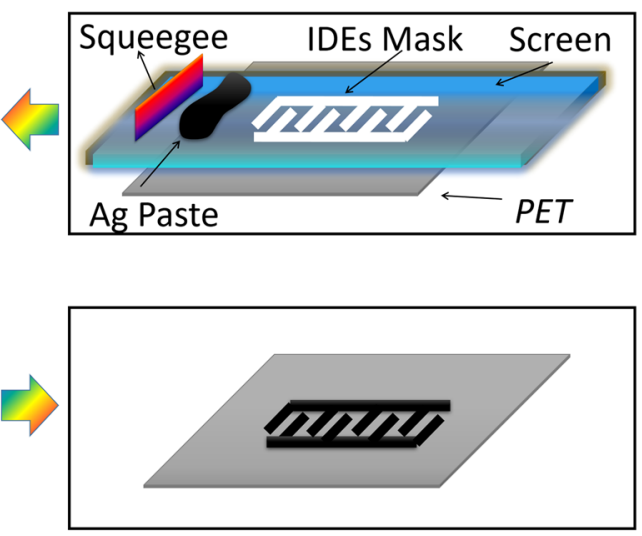

Printed Electrodes on PET

\section{(c) Simulated IDEs}

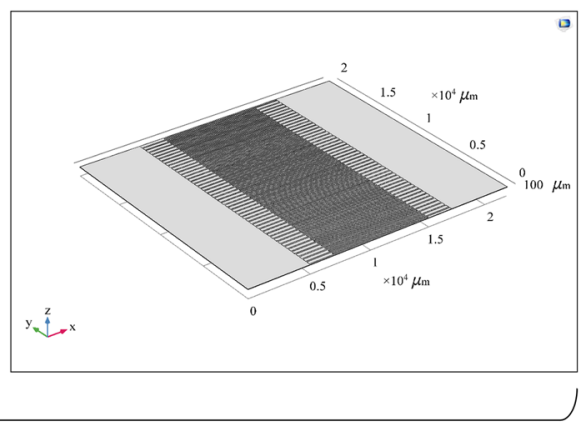

\section{(e) 3D Nano profile of IDEs}

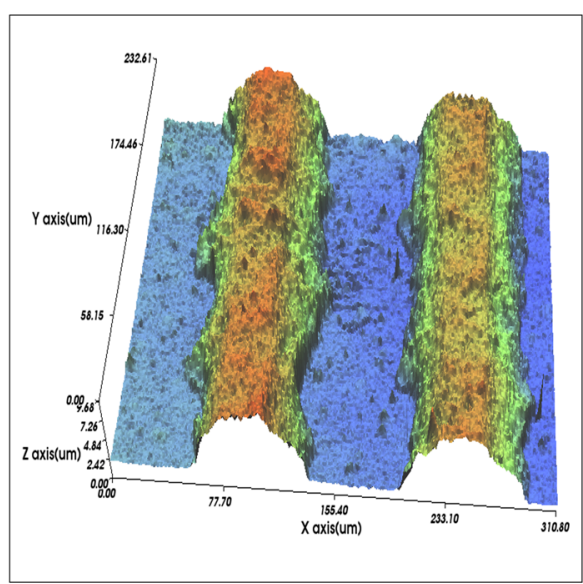

Figure 1. Printing process and Nano-profiles. (a) Screen Printing of Ag ink to form IDEs on PET substrate. (b) Fabricated sensor. (c) Simulated sensor. (d) 2D Nano profile of IDEs. (e) 3D Nano profile of IDEs.

and $\mathrm{O}$ bonds, but also water penetration between the layered formation becomes easy as compared to Bulk and Nano-flower solid centre cores ${ }^{12}$. Absorption of water molecules shifts the Fermi energy from semiconductor nature of $\mathrm{MoSe}_{2}{ }^{26,43}$ towards conduction band ${ }^{12}$. Increasing the number of free electrons and hence a higher electrical conductivity of the sensing sheet ${ }^{12,44}$. Enhanced surface roughness of $\mathrm{MoSe}_{2}$ nano-flakes helps to increase the sensitivity of the sensor, as earlier reported for same family of materials ${ }^{13}$, making a large surface area resulting in higher molecular bonding rate. Further explanation of sensing mechanism is added in the supplementary information. In other words, with the increase of humidity level the capacitance of the device increases as a result the impedance of device decreases. 

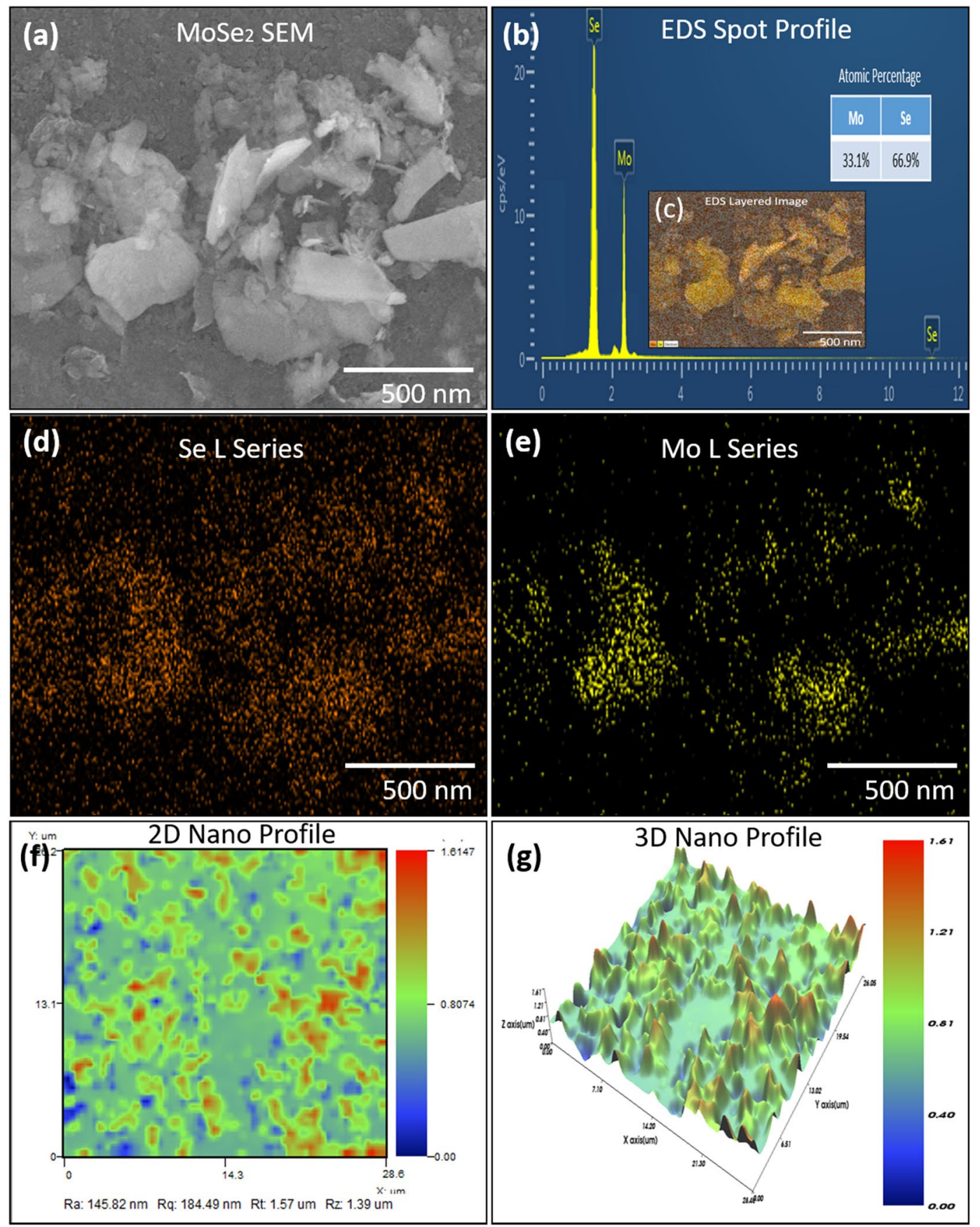

Figure 2. (a) $\mathrm{MoSe}_{2}$ nano-flakes SEM image. (b) EDS spot profile and EDS mapped image and (c) EDS layered image. (d) Se L series and (e) Mo L series. (f) 2D Nano profile image showing surface roughness and (g) 3D Nano profile showing height profile of $\mathrm{MoSe}_{2}$.

The equivalent circuit ${ }^{45}$ given in Fig. $3, C_{d l}$ represents the double layer capacitance, $R_{s}$ shows the sheet resistance, and $C_{d}$ is the dielectric behavior of the humid air above sensor surface. The sheet resistance and capacitance are calculated as Eqs. (1) and (2) ${ }^{45}$.

$$
R_{s}=\frac{1}{n l k} \frac{2 K\left(\sin \left(\frac{\pi w_{s p}}{2 L}\right)\right)}{K \cos \left(\left(\frac{\pi w_{s p}}{2 L}\right)\right)}
$$




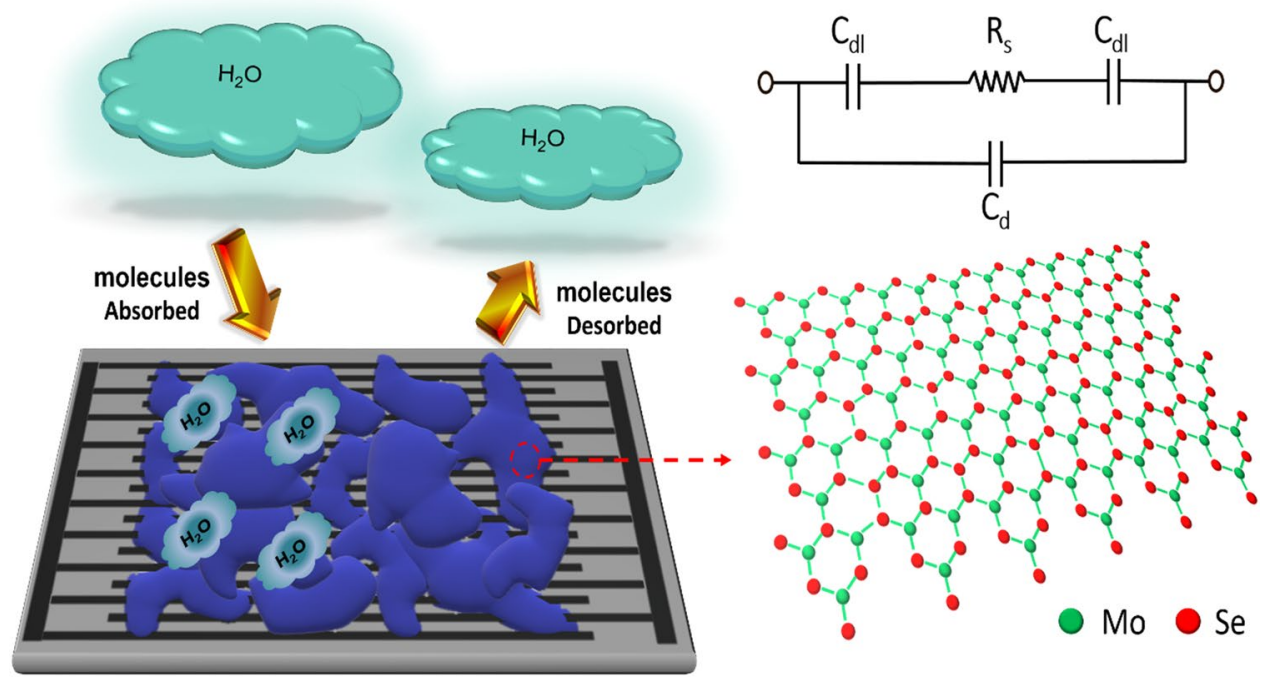

Figure 3. Sensing mechanism based on $\mathrm{MoSe}_{2}$ nano-flakes and its equivalent circuit.

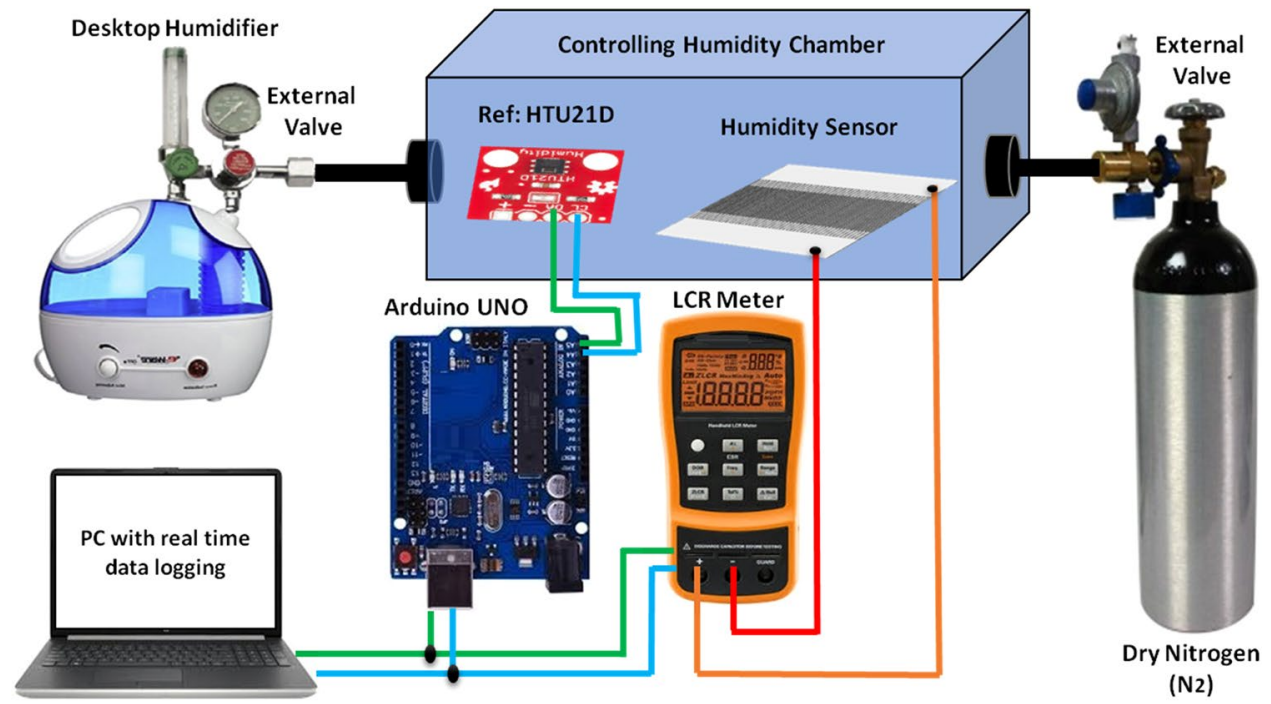

Figure 4. Experimental setup block diagram.

$$
C_{d l}=n l \varepsilon \frac{2 K\left(\sin \left(\frac{\pi w_{s p}}{2 L}\right)\right)}{K \cos \left(\left(\frac{\pi w_{s p}}{2 L}\right)\right)}
$$

Here, $n$ is the number, $l$ is the length of IDE fingers, $k$ is the sheet conductivity, $w_{s p}$ is the electrode spacing, $L$ is the characteristic length equal to electrode spacing + width, and $\varepsilon$ is the relative permittivity. The resistance and capacitance thus become a function of the electrode spacing ratio $w_{s p /} L$. At low frequencies the impedance behavior is dominated by capacitive effect especially due to $C_{d l}$. Between frequencies $1-10 \mathrm{kHz}$ the impedance is a combination of resistive as well as capacitive effect ${ }^{45,46}$. Therefore, calculations were performed at $1 \mathrm{kHz}$ to incorporate the change in capacitive behavior under variating humidity conditions.

Measurement setup. To keep experimental setup, an airtight homemade box was used as humidity test box. To reduce the error margin a commercial HTU21D sensor with resolution of $0.04 \%$ RH with accuracy of $\pm 2 \% \mathrm{RH}$ with time response of $<5 \mathrm{~s}$ and temperature coefficient of $-0.15 \% \mathrm{RH} /{ }^{\circ} \mathrm{C}$ was used as reference sensor. The measurement setup included a KEYSIGHT Digital U1700C hand held LCR meter with an Arduino UNO as control setup, and for increase and decrease in humidification, humidifier and dry nitrogen $\left(\mathrm{N}_{2}\right)$ were utilized respectively as shown in Fig. 4. For data acquisition, personal computer (PC) was used while the fabricated sensor 
data was analyzed on built-in-software of KEYSIGHT Digital U1700C hand held LCR meter. The reference logging data were performed on cool term software with OriginPro 8.0 for plotting graphs. Both the Arduino UNO and LCR meter were connected through Universal Serial Bus (USB) Port with PC for automatic data logging. Commercial humidifier increases the humidity level from $0 \%$ to $90 \%$ inside the humidity box while dry $\mathrm{N}_{2}$ with external control valve dehumidifies the box. Experiments were performed from 20 to $30^{\circ} \mathrm{C}$ with a step size of $5^{\circ} \mathrm{C}$. For transient response measurement, a sudden increase from 0 to $90 \% \mathrm{RH}$ and sudden decrease from $90 \%$ to $0 \%$ $\mathrm{RH}$ was executed. Figure 4 represents the complete block diagram of experimental setup.

Simulation setup. The sensor based on three-dimensional structure was designed on COMSOL Multiphysics 5.3a software platform. Two physics modules/disciplines were assigned to the model namely electrostatics and moisture transport. Impedance calculations were performed through electrostatics module while the moisture absorption, desorption, and change in relative permittivity of sensing layer are studied through the moisture transport module. Materials were assigned to individual layers, while the parameters for sensing layer were defined through material property functions. To minimize simulation time, a free-tetrahedral meshing topology was utilized with largest possible sizing for relatively reduced number of degrees of freedom. A time dependent study analysis was chosen for the investigation of relative humidity $(\mathrm{RH})$ for better understanding of absorption process. The open surface area was exposed to different humidity levels ranging from $0 \sim 90 \% \mathrm{RH}$ with a step size of $5 \%$. As the humidity level increases the vapor concentration $\left(\mathrm{mols} / \mathrm{m}^{3}\right)$ increases, hence absorbed water content by the sensor does not remain at equilibrium and water molecules start to diffuse in the sensing layer. This phenomenon is shown in Fig. S7a,b of supplementary information, where water content at $0 \% \mathrm{RH}$ and $90 \% \mathrm{RH}$ levels is represented, respectively. Simulation and design details are provided in supporting information file.

\section{Results and Discussion}

The effect of absorption of $\mathrm{H}_{2} \mathrm{O}$ molecules on electrical properties of $\mathrm{MoSe}_{2}$ sensing layer was studied by impedance and capacitance measurements in a homemade airtight box utilized as humidity chamber. In this experiment, a step wise change in temperature $(T)$ and $\mathrm{RH}$ were performed in a controlled way $\left(T\right.$ range $20-30^{\circ} \mathrm{C}$ with $5^{\circ} \mathrm{C}$ step size and $\mathrm{RH}$ range of $\left.0-90 \%\right)$. Multiple sensors were fabricated and their response was recorded as shown in Fig. S10 of Supplmentary Information. which shows the sensor can be mass produced and is highly reproducable. Four types of response analysis included impedance, capacitance, hysteresis and transient response discussed in subsections below:

Impedance response. As the temperatures rises, the kinetic energy of molecules increases as well as gas pressure, and vice versa, the diffusion rate of water molecules in $\mathrm{MoSe}_{2}$ changes with the variating ambient temperature. The gas pressure is expressed as in Eq. (3):

$$
P V_{v o l}=n R T
$$

where, $P$ is the vapour pressure, $T$ is temperature, $n$ is number of moles, $V_{v o l}$ is volume, and $R$ is ideal gas constant. Deriving from Eq. (3), the average kinetic energy $\left(K E_{\text {avg }}\right)$ dependence on temperature can be calculated as in Eq. (4):

$$
K E_{\text {avg }}=\left[\frac{1}{2} m v^{2}\right]=\frac{3}{2} k T
$$

where, $m$ is the mass, $v$ is the velocity of molecules, and $k$ is a ratio of gas constant over Avogadro's number. The above equations are related to translational energy of molecules. As the kinetic energy of gas molecules increases with increase in temperature, even at lower $\mathrm{RH}$ the water molecules diffuse into the senstive layer and cause reduction in impedance. To analyze this dependence, different temperature levels ranging from 20 to $30^{\circ} \mathrm{C}$ were simulated with a step size of $5^{\circ} \mathrm{C}$, which explain higher intermolecular interactions and binding with $\mathrm{MoSe}_{2}$ layer due to higher kinetic energy of water molecules. The impedance based simulated and practical results are presented in Fig. 5a,b. The volcano plots suggest ${ }^{47,48}$ a higher exchange current for $\mathrm{MoSe}_{2}$ for the above mentioned phenomenon. Thus, increase in humidity decreases the impedance of the sensing layer. $\mathrm{MoSe}_{2}$ general impedance is given in the Eq. (5).

$$
Z=R+\frac{1}{j 2 \pi f C}
$$

where, $j=\sqrt{-1}, f$ is the frequency, $R$ is the resistance of wires, and $C$ is the capcitance. In this study, the measured and theoretical impedance are described as absolute value $(|Z|)$ without a phase information from Eq. (5). The impedance changes slightly till $20 \% \mathrm{RH}$ due to low concentration of $\mathrm{H}_{2} \mathrm{O}$ molecules, and lesser number of molecular interacting with sensing layer. Impedance rapidly decreases as $\mathrm{RH}$ increases between $20 \%$ and $90 \%$, which can be contributed to adequate number of molecular contentration of $\mathrm{H}_{2} \mathrm{O}$ for interaction with the $\mathrm{MoSe}_{2}$ with enough free electrons contribuing to lower electrical resistance.

The high density of exfoliated nano-flake edges allows a semiconducting to metallic phase transition ${ }^{31}$. Exfoliated nano-flakes are more disorderly placed as compared to nano-flower structures ${ }^{31}$. Hence, a simple exfoliation process enhances the chemical reactivity of $\mathrm{MoSe}_{2}$ as compared to grown nano-structures with solid center cores $^{31}$. The bond lengths of Se-H bond were calculated as $1.48 \AA^{30}$ and the Se egde shows a very weak hydrogen binding energy ${ }^{30}$. $\mathrm{MoSe}_{2}$ has a lower $\varphi$ and its Fermi energy lies closer to normal hydrogen electrode ${ }^{30}$. This allows a much easier exchange of outer most electron at the Se edge. Above $90 \% \mathrm{RH}$, the proposed sensor reaches saturation of intermolecular interactions. The details for our simulation are described in the Supplementary 

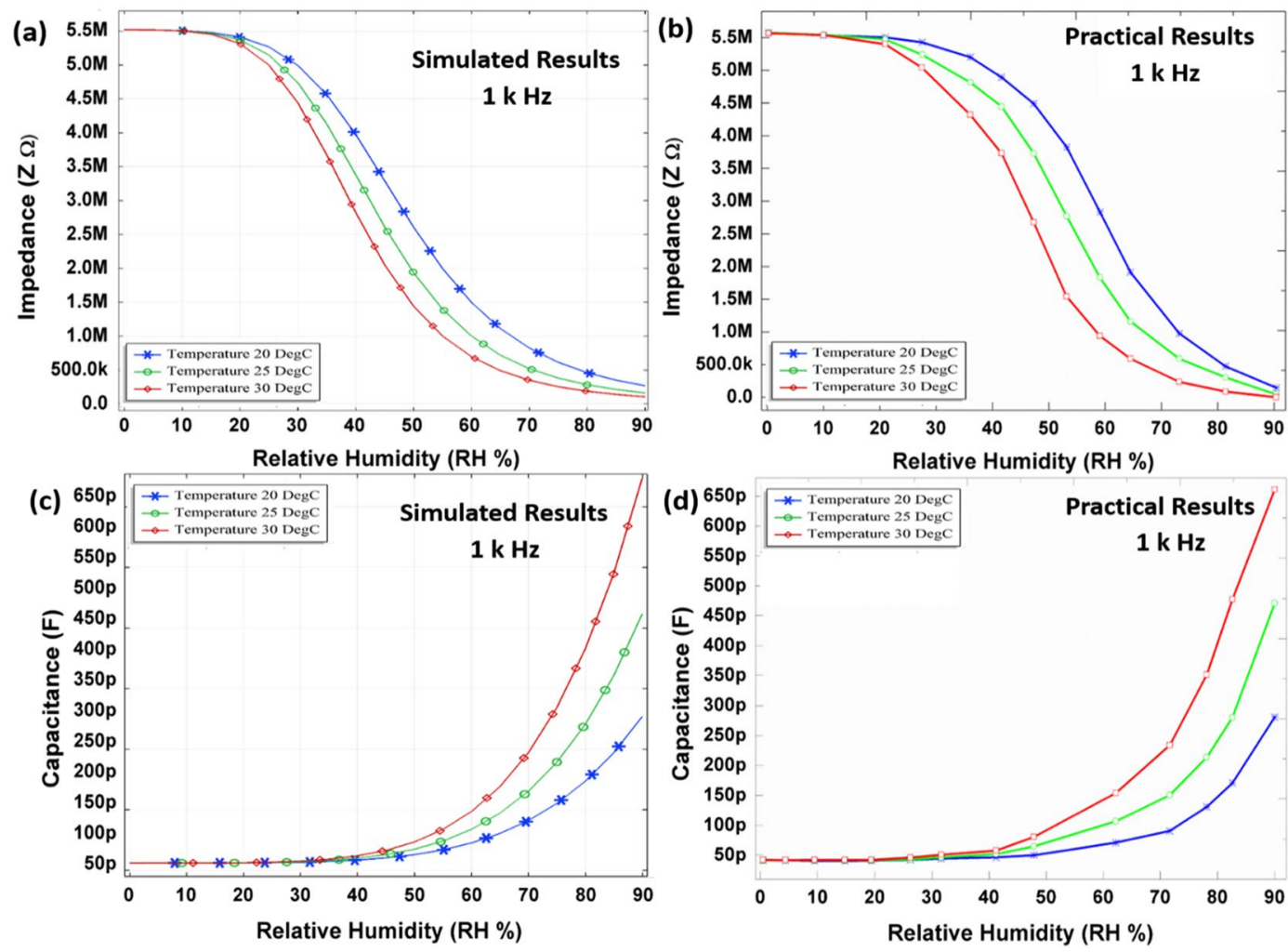

Figure 5. (a) Simulated impedance analysis and (b) practical impedance analysis of $\mathrm{MoSe}_{2}$. (c) Simulated capacitance and (d) practical capacitance analysis of $\mathrm{MoSe}_{2}$.

information file. The small difference between the simulated and practical results was observed, hence we can say that the theoretical values were matched quiet well with the practical ones in aspect of design. It is attributed to large surface area, void spaces and surface roughness of $\mathrm{MoSe}_{2}$ nanoflakes, which contributes to the higher molecular bondings, while larger surface area gives a higher saturation limit in $\mathrm{RH}$ as earlier reported for same family materials ${ }^{13}$.

Capacitance response. The sensing layer is a semiconductor material, and its dielectric constant changes with the amount of water content absorbed by the layer. This change in dielectric constant, here, was measured as a change in capacitance by energizing the electrode structure. The capacitance based theroetical and practical results are presented in Fig. $5 \mathrm{c}, \mathrm{d}$, repectively, at $1 \mathrm{kHz}$ with temperature levels ranging from 20 to $30^{\circ} \mathrm{C}$ with a step size of $5^{\circ} \mathrm{C}$. The capacitance of humidity sensor increases while impedance decreases. Therefore, an electric potential of $0.6 \mathrm{~V}$ was applied across the IDEs to energize the sensor structure, as a result leakage current flows through IDEs and the resistance of the capacitor decreases. The effective capacitance $\left(C_{e f f}\right)$ of the humidity sensor is presented in Eq. (6).

$$
C_{e f f}=\varepsilon^{*} C_{o}=\left(\varepsilon_{r}-j\left(\gamma / 2 \pi f \varepsilon_{o}\right)\right) C_{o}
$$

where, $\varepsilon^{*}, \varepsilon_{r}, \varepsilon_{o}, C_{0}$, and $\gamma$ are the complex dielectric constant, relative permittivity of ideal capacitor, dielectric constant of free space, expected capacitance, and conductance, respectively as given in Eq. (6). Water molecules make bonds on the Mo and Se edges of the nano-flakes and this causes change in relative permittivity of the sensing layer with higher hydrogen bonds created under higher water concentration. Figure 6a represents the simulation results of the applied electric potential across the IDEs, and an electric field, consequently, is formed between the electrodes as represented in Fig. 6b. The increase in dielectric constant of the $\mathrm{MoSe}_{2}$ layer, due to increase in water concentration, initiates a unique phenomenon that more charge is stored at electrode surfaces. This increased capacity of storing charge enhances the overall capacitance and represented by Eqs. (7) and (8), where, $Q$ is the terminal charge, $V_{\text {bias }}$ is the biasing or applied voltage, and $C_{s}$ is the capacitance of the system. Further capacitance and energy related simuation results are discussed in the Supplementary information file.

$$
\begin{gathered}
Q=C_{s} V_{\text {bias }} \\
C_{s}=Q / V_{\text {bias }}=\varepsilon_{o} \varepsilon_{r} A / d
\end{gathered}
$$

Sensitivity and sizing tradeoff. Sensitivity of the sensor here is defined by the Eqs. (9) and (10) $)^{49-52}$. Here, $Z_{u}, Z_{b}$, $C_{u}$, and $C_{l}$ are the upper and lower limits of the magnitude of impedance and capacitance, respectively, and $R H_{u}$ 


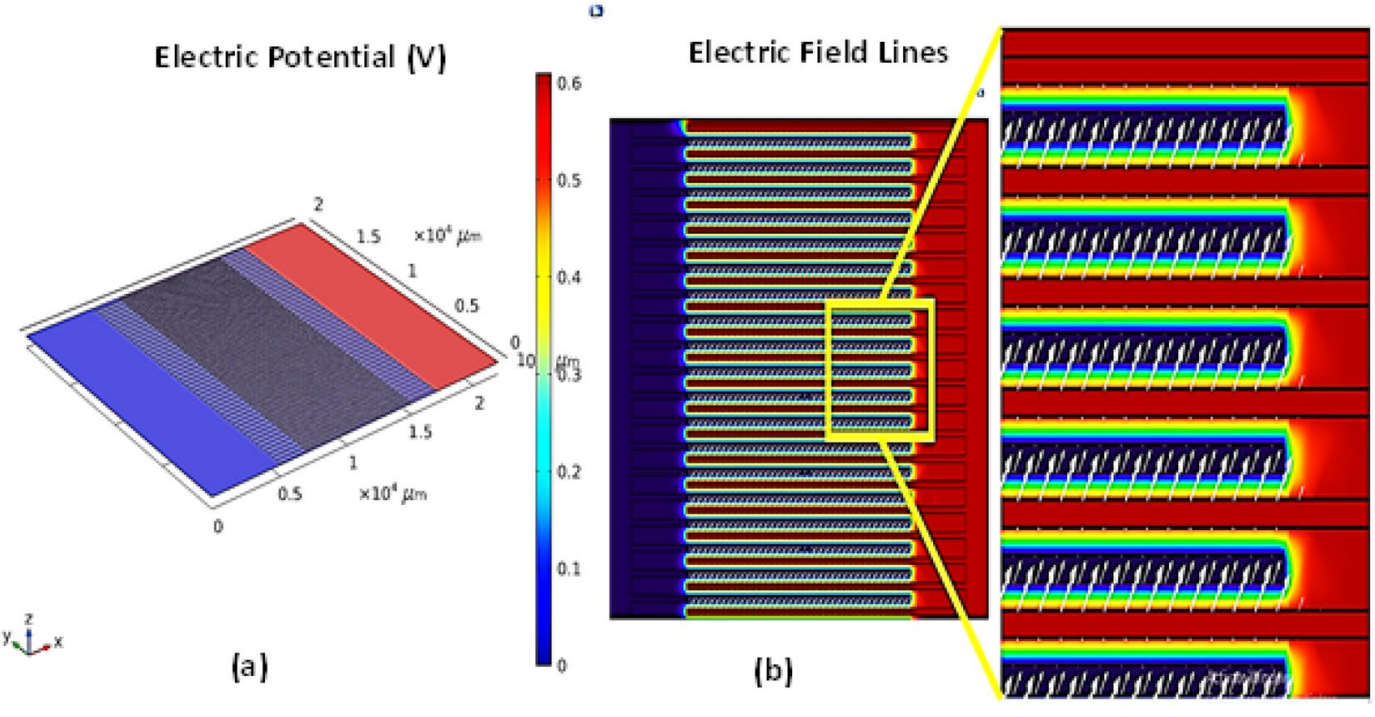

Figure 6. (a) 0.6 V electric potential applied across IDEs. (b) Electric field between IDEs.
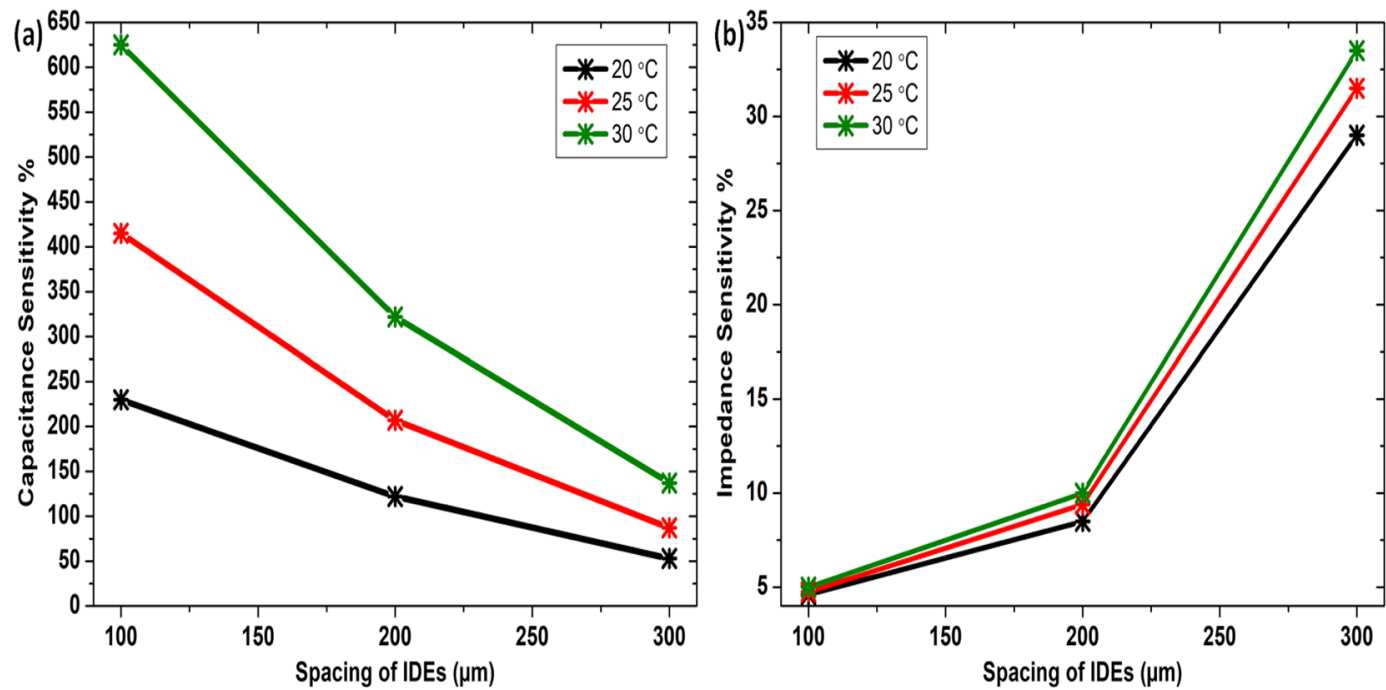

Figure 7. Sensitivity w.r.t. IDEs spacing of (a) capacitive and (b) impedance.

and $\mathrm{RH}_{l}$ are the upper and lower limits of relative humidity, respectively. These Eqs. (9) and (10) are employed to calculate the sensitivities of the sensor.

$$
\begin{aligned}
& S=\frac{\left(C_{u}-C_{l}\right)}{\left(R H_{u}-R H_{l}\right)} \times 100 \\
& S=\frac{\left(Z_{u}-Z_{l}\right)}{\left(R H_{u}-R H_{l}\right)} \times 100
\end{aligned}
$$

Figure $7 \mathrm{a}$ shows sensitivities calculated for capacitance measurements and Fig. $7 \mathrm{~b}$ shows sensitivities for impedance measurements for temperature range from $20-30^{\circ} \mathrm{C}$ obtained at different IDEs spacing in the range $100-300 \mu \mathrm{m}$. A tradeoff is observed from sensitivity calculations, if tried to further increase the capacitance response the sensitivity of the sensor in terms of impedance reduces and vice versa. It directly follows the below mentioned behavior in Eq. (11), capacitance, $C$ is inversely proportional to the impedance, $Z$. Hence, a spacing size of $100 \mu \mathrm{m}$ is chosen having highest capacitance in $\mathrm{pF}$ range and lowest impedance in $\mathrm{M} \Omega$ range.

$$
Z \propto 1 / C
$$



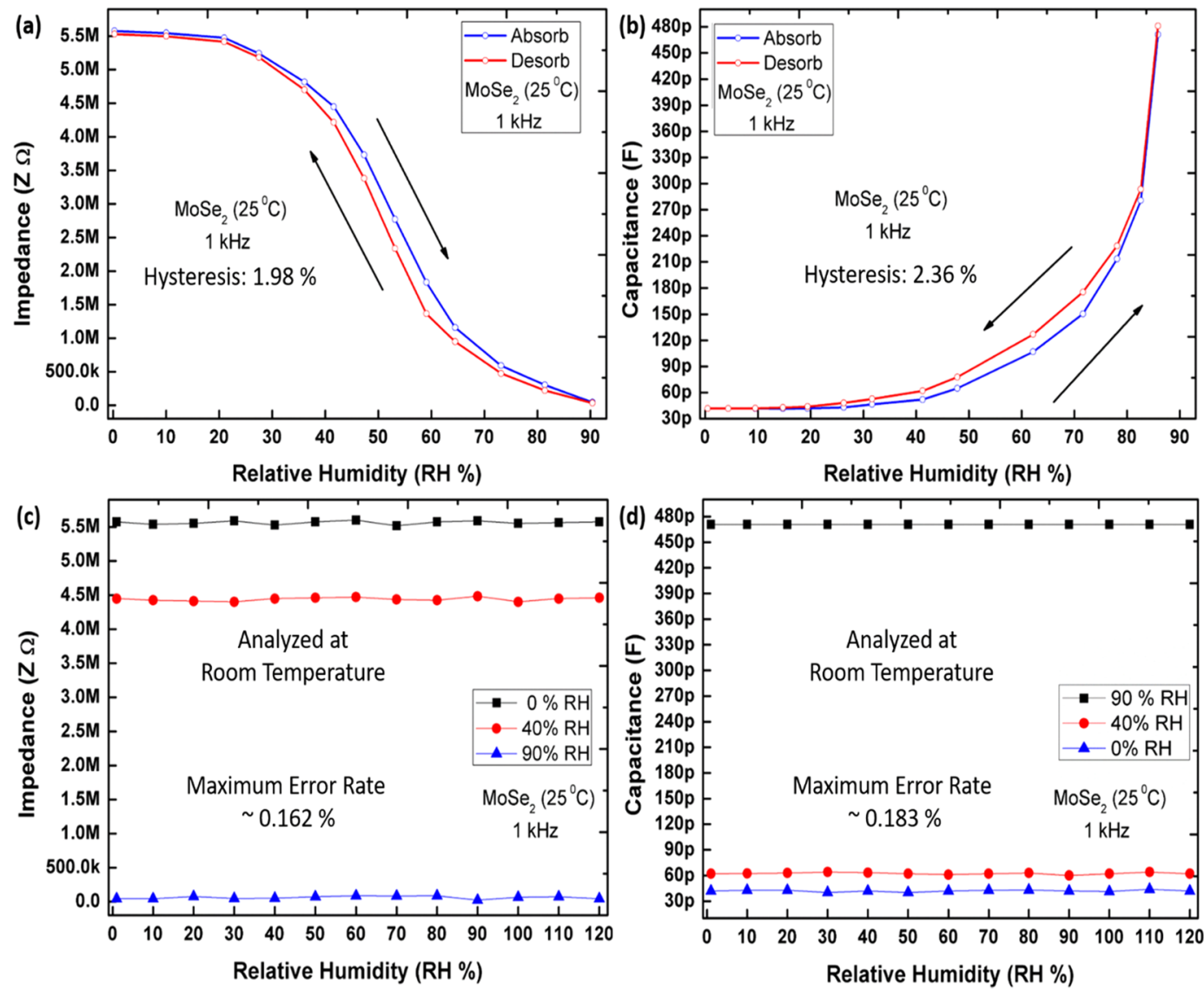

Figure 8. Hysteresis and Stability (a) Impedance hysteresis study, (b) capacitance hysteresis study, (c) impedance stability, and (d) capacitance stability.

Hysteresis and stability analysis. Hysteresis is caused due to trapping of charges between the molecular gaps, which is injected from/to the interfaces between semiconductor, substrate, and adsorbates. Hysteresis effect in $\mathrm{MoS}_{2}$ has been reported due to major $\mathrm{S}-\mathrm{H}$ atom interatctions and water molecules are considered to be the major cause of hysteresis. Water molecules form a large electric dipole of $\sim 1.8 \mathrm{D}$ and can align under electric field to form polar molecular structure. This structural alignment causes different charge trap densities and hence causing hyesteresis ${ }^{20}$. Similar is the case for $\mathrm{MoSe}_{2}$ which has much weaker $\mathrm{Se}-\mathrm{H}$ bond. The impedance and capacitance based hysteresis characteristics are shown in Fig. 8a,b, respectively. Initially, the sensor was placed at $0 \% \mathrm{RH}$, then humidity level was ramped from 0 to $90 \% \mathrm{RH}$, and back from 90 to $0 \% \mathrm{RH}$. Both impedance and capacitance of the sensor were recorded during adsorption and desorption cycles. Average hysteresis was calculated by using Eq. (12).

$$
\text { Average Hysteresis }=\left[\sum_{k=0}^{n}\left(y_{k+1}-y_{k}\right) /\left(y_{\max }-y_{\min }\right)\right] / n
$$

Here, $y_{k} k=\{0,1, \cdots, n\}$ is impedance at $k$ th test point, and $y_{\max }$ and $y_{\min }$ are maximum and minimum impedance values, respectively, in number $n$ test points data. The percentage hysteresis during humidification and dehumidification of impedance and capacitance are stated on each graph curvature presented in Fig. 8a,b, respectively. Impedance and capacitance values during desorption cycle lower $\mathrm{RH}(0 \sim 30 \%)$ show no hyeteresis due to very low $\mathrm{H}_{2} \mathrm{O}$ concentration. While, the upper $(80 \sim 90 \%)$ values are overlapping which again shows no hysteresis, due to saturation of $\mathrm{H}_{2} \mathrm{O}$ in atmosphere. In range of $30-80 \% \mathrm{RH}$ the curve follows different impedance and capacitance paths contributed to varying $\mathrm{H}_{2} \mathrm{O}$ concentration, and hence different $\mathrm{Se}-\mathrm{H}$ interactions. The impedance and capacitance stability and repeatability was investigated by keeping the humidity sensor in different ambient conditions of $90 \% \mathrm{RH}, 40 \% \mathrm{RH}$ (open air response) and $0 \% \mathrm{RH}$ for $120 \mathrm{~min}$ as shown in Fig. 8c,d. The stable impedance and capcitance response was recorded with maximum error rate of $\sim 0.162 \%$ and $0.183 \%$, respectively.

Transient response. As shown in Fig. 9, the recorded transient response of the sensors facilitates investigation of response time $\left(T_{\text {res }}\right)$ and recovery time $\left(T_{\text {rec }}\right)$ of the sensor during humidification and dehumidification. The transient response indicates sensitivity of sensor on sudden change in humidity levels in environment. As shown in Fig. 9a the impedance response of humidity sensor on longer scale showing $T_{\text {res }} \sim 0.96 \mathrm{~s}$ and $T_{\text {rec }} \sim 1.03 \mathrm{~s}$ respectively, as shown in Fig. 9b. The capacitance response of humidity sensor on longer scale As shown in Fig. $9 \mathrm{c}$ showing $T_{\text {res }} \sim 1.87 \mathrm{~s}$ and $T_{\text {rec }} \sim 2.13 \mathrm{~s}$, respectively, as shown in Fig. $9 \mathrm{~d}$. To compare the findings of MoSe $\mathrm{e}_{2}$ based humidity sensor with other reported sensors, Table 1 shows the comparison on the basis various characteristics 

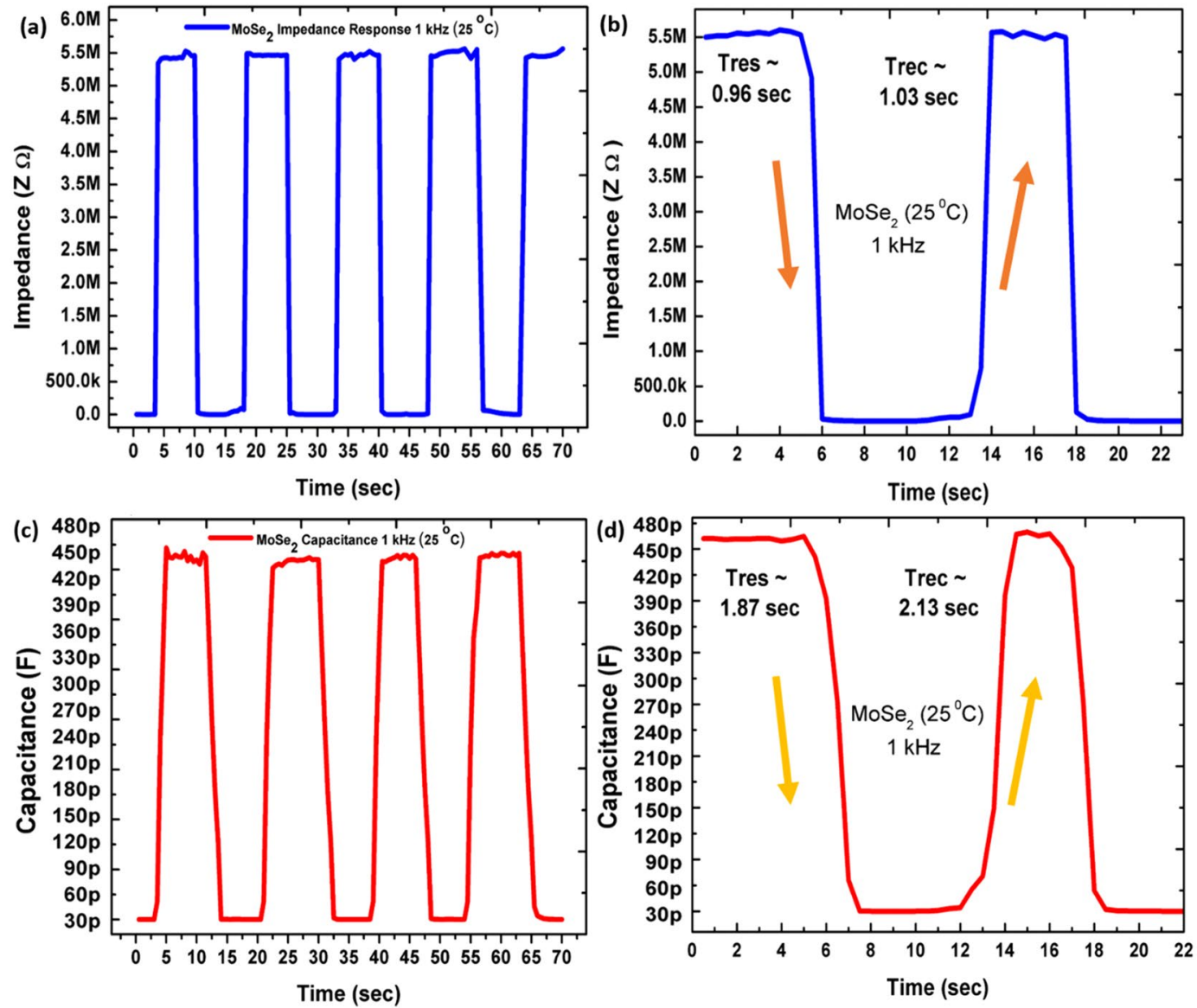

Figure 9. (a) Impedance response on longer scale showing, (b) reponse time of $0.96 \mathrm{~s}$ and recovery time of $1.03 \mathrm{~s}$. (c) Capacitance response on longer scale showing, (d) response time of $1.87 \mathrm{~s}$, and recovery time of $2.13 \mathrm{~s}$.

include fabrication technique, response time, recovery time, range, materials, and the sensitivity of the sensors. The graphene and $\mathrm{ZnO}$ composite sensor ${ }^{53}$ is targeted as a wide range from 0 to $85 \% \mathrm{RH}$, but presented a mismatch in response and recovery times. In Table 1, the bio-compatible research works ${ }^{54,55}$ have the advantage of wide application range, but they have a large difference in response and recovery times of approximately 11 and 4 times, respectively. A big difference in response time requires a complex control structure and restrict its usage for real time applications. The fourth listed work is a tough competitor with respect to response and recovery time; however, it has a range from $15 \%$ to $78 \%{ }^{39}$. The best possible real time monitoring sensor for health services and applications (breath test) ${ }^{11}$ has a narrower range from $30 \%$ to $80 \%$ RH. Sixth in the list presents chemical etching and dispersion process that requires extra care while handling with acids ${ }^{56}$, and cannot be directly printed. Seven, eight and nine listed works ${ }^{13,57,58}$ belong to the same material family of $\mathrm{MoSe}_{2}$, but present a far inferior response to $\mathrm{MoSe}_{2}$ in term of range and in response and recovery time. Tenth, inkjet-printed black phosphorus has a wide range, but a slow response time of $4.7 \mathrm{~s}^{59}$. Lastly, $\mathrm{MoSe}_{2}$ nano-flower structure was fabricated with a wide range of $0-97 \% \mathrm{RH}$, but again lacked in response and recovery times ${ }^{12}$. Here, we have targeted a wider range between $20 \%$ and $90 \% \mathrm{RH}$ with fast and equivalent time response of $1 \mathrm{~s}$ approximately, which makes it suitable for real time monitoring and control applications. The difference between response and recovery time is small, hence this designed sensor is suitable with a simpler control and monitoring circuitry. The presented sensor gives a maximum detection of 30 breaths/min, keeping in mind that average breathing rate at rest in adults is $12-18$ breaths/ $\min ^{60}$. A human breath detection test is performed and video is provided in Supplementary information. The ultrasensitive moisture response of $\mathrm{MoSe}_{2}$ sensor allows its utility in applications like contactless switch as shown in Fig. 10a. The humidity sensor shows a rapid real-time change of capacitance (up to $260 \mathrm{pF}$ ) at $1 \mathrm{kHz}$ after placing a finger approximately $6 \mathrm{~mm}$ above the device as shown in Fig. 10b. The ultrasensitive capacitive response of the $\mathrm{MoSe}_{2}$ humidity sensor allows the capture of moisture from surface of human fingertip. If the finger is covered with tape, the sensor shows no response to the presence of the finger.

\section{Conclusion}

In this work, we demonstrated a highly stable, wide range and superfast humidity sensor based on $\mathrm{MoSe}_{2}$ utilizing a thin and highly rough surface sensitive layer for fast response. From this fabricated sensor, the impedance and capacitance change are recorded in range from $0 \% \mathrm{RH}$ to $90 \% \mathrm{RH}$ with different temperature levels ranging from $20^{\circ} \mathrm{C}$ to $30^{\circ} \mathrm{C}$. The impedance and capacitance hysteresis recorded was $<1.98 \%$ and $<2.36 \%$, respectively. The 


\begin{tabular}{|c|c|c|c|c|c|c|c|c|}
\hline $\begin{array}{l}\text { S. } \\
\text { No }\end{array}$ & $\begin{array}{l}\text { Article } \\
\text { Reference }\end{array}$ & Sensor Type & Fabrication Process & Range & $\begin{array}{l}\text { Response } \\
\text { Time }\end{array}$ & $\begin{array}{l}\text { Recovery } \\
\text { Time }\end{array}$ & Material Type & Sensitivity \\
\hline 1 & 53 & Impedance & Inkjet Printing & $0-85 \%$ & $1 \mathrm{~s}$ & $2 \mathrm{~s}$ & $\begin{array}{l}\text { Graphene and } \mathrm{ZnO} \\
\text { Composite }\end{array}$ & $\begin{array}{l}\text { High Sensitivity } \\
>60 \%\end{array}$ \\
\hline 2 & 54 & Impedance & Screen Printing & $0-80 \%$ & $1 \mathrm{~s}$ & $10.75 \mathrm{~s}$ & $\begin{array}{l}\text { Single Cell thick } \\
\text { Onion membrane }\end{array}$ & $\begin{array}{l}\text { High Sensitivity } \\
>50 \%\end{array}$ \\
\hline 3 & 55 & $\begin{array}{l}\text { Impedance and } \\
\text { Capacitance } \\
\text { based }\end{array}$ & Inkjet Printing & $0-90 \%$ & $1.99 \mathrm{~s}$ & $8.76 \mathrm{~s}$ & Egg shell membrane & $\begin{array}{l}\text { High Sensitivity } \\
\text { between } \\
40-70 \%\end{array}$ \\
\hline 4 & 39 & Resistance & Spin Coating & $15-78 \%$ & $1.78 \mathrm{~s}$ & $0.45 \mathrm{~s}$ & Lead free $\mathrm{Cs}_{2} \mathrm{BiAgBr}_{6}$ & $\begin{array}{l}\text { High Sensitivity } \\
>60 \%\end{array}$ \\
\hline 5 & 11 & Impedance & Screen Printing & $30-80 \%$ & $30 \mathrm{~ms}$ & $30 \mathrm{~ms}$ & $\begin{array}{l}\text { Graphene Oxide } \\
15 \text { nm layer }\end{array}$ & $\begin{array}{l}\text { Linear } \\
\text { Response } \\
\text { between } \\
35-75 \%\end{array}$ \\
\hline 6 & 56 & $\begin{array}{l}\text { Transmission } \\
\text { light Power }\end{array}$ & $\begin{array}{l}\text { Chemical etching and } \\
\text { dispersion }\end{array}$ & $20-80 \%$ & $0.066 \mathrm{~s}$ & $2.395 \mathrm{~s}$ & $\begin{array}{l}\mathrm{MoS}_{2} \text { coated etched } \\
\text { single mode fibre }\end{array}$ & $\begin{array}{l}0.94-1.06 \mathrm{~mW} \\
\text { Change } \\
\text { in Power } \\
\text { Consumption }\end{array}$ \\
\hline 7 & 57 & Resistance & Stamping & $0-100 \%$ & $30-40 s$ & $12-50 s$ & $\mathrm{VS}_{2}$ & $\begin{array}{l}\text { Highly } \\
\text { Sensitive > } \\
50 \%\end{array}$ \\
\hline 8 & 13 & Resistance & Drop Casting & $0-60 \%$ & $9 \mathrm{~s}$ & $17 \mathrm{~s}$ & $\mathrm{MoS}_{2}$ & $\begin{array}{l}\text { Between } \\
10-50 \%\end{array}$ \\
\hline 9 & 58 & Resistance & Thermal Evaporation & $40-80 \%$ & $13 \mathrm{~s}$ & $17 \mathrm{~s}$ & $\mathrm{WS}_{2}$ & $\begin{array}{l}\text { Between } \\
40-80 \%\end{array}$ \\
\hline 10 & 59 & Capacitance & Inkjet Printing & $11-97 \%$ & $4.7 \mathrm{~s}$ & $3.0 \mathrm{~s}$ & Black Phosphorus & $\begin{array}{l}\text { High Sensitivity } \\
>50 \%\end{array}$ \\
\hline 11 & 12 & Resistance & Hydrothermal Growth & $0-97 \%$ & $53 \mathrm{~s}$ & $13 \mathrm{~s}$ & $\mathrm{MoSe}_{2}$ nano-flower & $-74.41 \%$ \\
\hline 12 & This Work & $\begin{array}{l}\text { Impedance and } \\
\text { Capacitance } \\
\text { Based }\end{array}$ & Screen Printing & $20-90 \%$ & $0.96 \mathrm{~s}$ & $1.03 \mathrm{~s}$ & $\mathrm{MoSe}_{2}$ & $\begin{array}{l}\text { High Sensitivity } \\
>20 \%\end{array}$ \\
\hline
\end{tabular}

Table 1. Comparison Table.
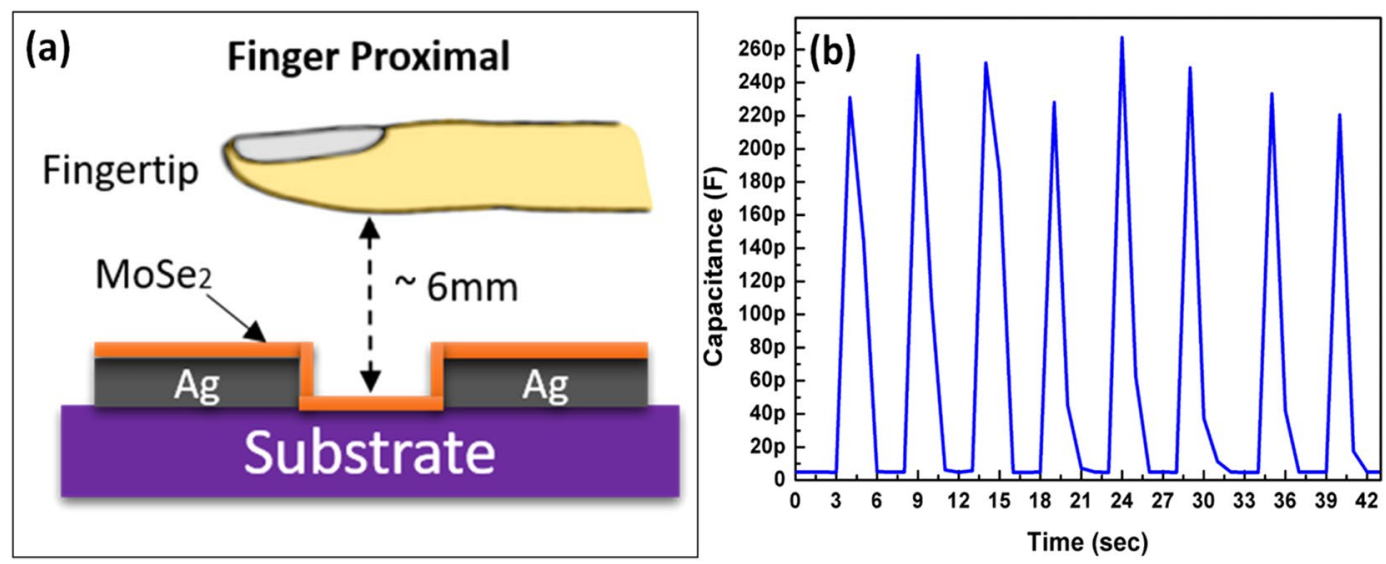

Figure 10. Contactless switch application (a) Experimental setup for contactless sensing of a proximal human fingertip. (b) $\mathrm{MoSe}_{2}$ sensor time-resolved proximal human fingertip test under ambient air conditions.

impedance stability recorded was with maximum error rate of $\sim 0.162 \%$ and capacitance stability analyzed was with maximum error rate $\sim 0.183 \%$. The designed sensor shows good performance with fast response and recovery times of $T_{\text {res }} \sim 0.96 \mathrm{~s}$ and $T_{\text {rec }} \sim 1.03 \mathrm{~s}$, respectively. Integration through inkjet printing technology is easily achievable for this sensor to monitor environmental and health services.

Received: 1 November 2019; Accepted: 12 March 2020;

Published online: 26 March 2020

\section{References}

1. Butler, S. Z. et al. Progress, challenges, and opportunities in two-dimensional materials beyond graphene. ACS nano 7, 2898-2926, https://doi.org/10.1021/nn400280c (2013).

2. Cho, B. et al. Charge-transfer-based gas sensing using atomic-layer MoS 2. Sci. Rep. 5, 8052, https://doi.org/10.1038/srep08052 (2015).

3. Castellanos-Gomez, A. Why all the fuss about 2D semiconductors? Nat. Photonics 10, 202-204, https://doi.org/10.1038/ nphoton.2016.53 (2016). 
4. Novoselov, K. S. et al. Two-dimensional gas of massless Dirac fermions in graphene. nature 438, 197, https://doi.org/10.1038/ nature04233 (2005).

5. Georgakilas, V. et al. Functionalization of graphene: covalent and non-covalent approaches, derivatives and applications. Chem. Rev. 112, 6156-6214, https://doi.org/10.1021/cr3000412 (2012).

6. Chou, K. S., Lee, C. H. \& Liu, B. T. Effect of microstructure of $\mathrm{ZnO}$ nanorod film on humidity sensing. J. Am. Ceram. Soc. 99, 531-535, https://doi.org/10.1111/jace.13994 (2016).

7. Duan, Z., Xu, M., Li, T., Zhang, Y. \& Zou, H. Super-fast response humidity sensor based on La0. 7SrO. 3MnO3 nanocrystals prepared PVP-assisted sol-gel method. Sens. Actuators B: Chem. 258, 527-534, https://doi.org/10.1016/j.snb.2017.11.169 (2018).

8. Fei, T., Dai, J., Jiang, K., Zhao, H. \& Zhang, T. Stable cross-linked amphiphilic polymers from a one-pot reaction for application in humidity sensors. Sens. Actuators B: Chem. 227, 649-654, https://doi.org/10.1016/j.snb.2016.01.038 (2016).

9. Agarwal, S. \& Sharma, G. Humidity sensing properties of (Ba, Sr) TiO3 thin films grown by hydrothermal-electrochemical method. Sens. Actuators B: Chem. 85, 205-211, https://doi.org/10.1016/S0925-4005(02)00109-0 (2002).

10. Wang, R., Wang, D., Zhang, Y. \& Zheng, X. Humidity sensing properties of Bi0. 5 (Na0. 85K0. 15) 0.5 Ti0. 97Zr0. $03 O 3$ microspheres: Eff. A B sites co-substitution. Sens. Actuators B: Chem. 190, 305-310, https://doi.org/10.1016/j.snb.2013.08.048 (2014).

11. Borini, S. et al. Ultrafast graphene oxide humidity sensors. ACS nano 7, 11166-11173, https://doi.org/10.1021/nn404889b (2013).

12. Shelke, N. T. \& Late, D. J. Hydrothermal growth of MoSe2 nanoflowers for photo-and humidity sensor applications. Sensors and Actuators A: Physical, 160-168, https://doi.org/10.1016/j.sna.2019.05.045 (2019).

13. Zhang, S.-L., Jung, H., Huh, J.-S., Yu, J.-B. \& Yang, W.-C. Efficient exfoliation of MoS2 with volatile solvents and their application for humidity sensor. J. Nanosci. Nanotechnol. 14, 8518-8522, https://doi.org/10.1166/jnn.2014.9984 (2014).

14. Late, D. J., Shirodkar, S. N., Waghmare, U. V. \& Dravid, V. P. \& Rao, C. Thermal Expansion, Anharmonicity and TemperatureDependent Raman Spectra of Single-and Few-Layer MoSe2 and WSe2. ChemPhysChem 15, 1592-1598, https://doi.org/10.1002/ cphc.201400020 (2014).

15. Ghatak, S., Pal, A. N. \& Ghosh, A. Nature of electronic states in atomically thin MoS2 field-effect transistors. Acs Nano 5, 7707-7712, https://doi.org/10.1021/nn202852j (2011).

16. Rout, C. S. et al. Superior field emission properties of layered WS 2-RGO nanocomposites. Sci. Rep. 3, 3282, https://doi.org/10.1038/ srep03282 (2013)

17. Braga, D., Gutierrez Lezama, I., Berger, H. \& Morpurgo, A. F. Quantitative determination of the band gap of WS2 with ambipolar ionic liquid-gated transistors. Nano Lett. 12, 5218-5223, https://doi.org/10.1021/nl302389d (2012).

18. Georgiou, T. et al. Vertical field-effect transistor based on graphene-WS 2 heterostructures for flexible and transparent electronics. Nat. Nanotechnol. 8, 100, https://doi.org/10.1038/nnano.2012.224 (2013).

19. Late, D. J. et al. Sensing behavior of atomically thin-layered MoS2 transistors. ACS Nano 7, 4879-4891, https://doi.org/10.1021/ nn400026u (2013).

20. Late, D. J., Liu, B., Matte, H. S., Dravid, V. P. \& Rao, C. N. Hysteresis in single-layer MoS2 field effect transistors. ACS Nano 6, 5635-5641, https://doi.org/10.1021/nn301572c (2012)

21. Late, D. J., Liu, B., Matte, H. R., Rao, C. \& Dravid, V. P. Rapid characterization of ultrathin layers of chalcogenides on $\mathrm{SiO} 2 / \mathrm{Si}$ substrates. Adv. Funct. Mater. 22, 1894-1905, https://doi.org/10.1002/adfm.201102913 (2012).

22. Larentis, S., Fallahazad, B. \& Tutuc, E. Field-effect transistors and intrinsic mobility in ultra-thin MoSe2 layers. Appl. Phys. Lett. 101, 223104, https://doi.org/10.1063/1.4768218 (2012).

23. Bernardi, M., Palummo, M. \& Grossman, J. C. Extraordinary sunlight absorption and one nanometer thick photovoltaics using twodimensional monolayer materials. Nano Lett. 13, 3664-3670, https://doi.org/10.1021/nl401544y (2013).

24. Eftekhari, A. Molybdenum diselenide (MoSe2) for energy storage, catalysis, and optoelectronics. Appl. Mater. Today 8, 1-17, https:// doi.org/10.1016/j.apmt.2017.01.006 (2017).

25. Kong, D. et al. Synthesis of MoS2 and MoSe2 films with vertically aligned layers. Nano Lett. 13, 1341-1347, https://doi.org/10.1021/ nl400258t (2013).

26. Kioseoglou, G., Hanbicki, A. T., Currie, M., Friedman, A. L. \& Jonker, B. T. Optical polarization and intervalley scattering in single layers of MoS 2 and MoSe 2. Sci. Rep. 6, 25041, https://doi.org/10.1038/srep25041 (2016).

27. Chang, Y. H. et al. Monolayer MoSe2 grown by chemical vapor deposition for fast photodetection. ACS Nano 8, 8582-8590, https:// doi.org/10.1021/nn503287m (2014).

28. Ceballos, F., Bellus, M. Z., Chiu, H.-Y. \& Zhao, H. Ultrafast charge separation and indirect exciton formation in a MoS2-MoSe2 van der Waals heterostructure. ACS nano 8, 12717-12724, https://doi.org/10.1021/nn505736z (2014).

29. Kubart, T., Polcar, T., Kopecký, L., Novak, R. \& Novakova, D. Temperature dependence of tribological properties of MoS2 and MoSe2 coatings. Surf. Coat. Technol. 193, 230-233, https://doi.org/10.1016/j.surfcoat.2004.08.146 (2005)

30. Gupta, U. et al. Characterization of few-layer 1T-MoSe2 and its superior performance in the visible-light induced hydrogen evolution reaction. APL. Materials 2, 092802, https://doi.org/10.1063/1.4892976 (2014).

31. Lukowski, M. A. et al. Enhanced hydrogen evolution catalysis from chemically exfoliated metallic MoS2 nanosheets. J. Am. Chem. Soc. 135, 10274-10277, https://doi.org/10.1021/ja404523s (2013).

32. Yang, C.-P., Yin, Y.-X. \& Guo, Y.-G. Elemental selenium for electrochemical energy storage. J. Phys. Chem. Lett. 6, 256-266, https:// doi.org/10.1021/jz502405h (2015).

33. Jariwala, D., Sangwan, V. K., Lauhon, L. J., Marks, T. J. \& Hersam, M. C. Emerging device applications for semiconducting twodimensional transition metal dichalcogenides. ACS Nano 8, 1102-1120, https://doi.org/10.1021/nn500064s (2014).

34. James, P. B. \& Lavik, M. The crystal structure of MoSe2. Acta Crystallogr. 16, 1183-1183, https://doi.org/10.1107/ S0365110X6300311X (1963).

35. Late, D. J., Doneux, T. \& Bougouma, M. Single-layer MoSe2 based NH3 gas sensor. Appl. Phys. Lett. 105, 233103, https://doi. org/10.1063/1.4903358 (2014).

36. Shaw, J. C. et al. Chemical vapor deposition growth of monolayer MoSe 2 nanosheets. Nano. Research 7, 511-517, https://doi. org/10.1007/s12274-014-0417-z (2014).

37. Kohara, N., Nishiwaki, S., Hashimoto, Y., Negami, T. \& Wada, T. Electrical properties of the Cu (In, Ga) Se2/MoSe2/Mo structure. Sol. Energy Mater. Sol. Cell 67, 209-215, https://doi.org/10.1016/S0927-0248(00)00283-X (2001).

38. Tongay, S. et al. Thermally driven crossover from indirect toward direct bandgap in 2D semiconductors: MoSe2 versus MoS2. Nano Lett. 12, 5576-5580, https://doi.org/10.1021/nl302584w (2012)

39. Weng, Z. et al. Lead-Free Cs2BiAgBr6 Double Perovskite-Based Humidity Sensor with Superfast Recovery Time. Advanced Functional Materials, 1902234, https://doi.org/10.1002/adfm.201902234 (2019).

40. Yang, M. et al. Polymer electrolytes as humidity sensors: progress in improving an impedance device. Sens. Actuators B: Chem. 86, 229-234, https://doi.org/10.1016/S0925-4005(02)00190-9 (2002).

41. Seiyama, T., Yamazoe, N. \& Arai, H. Ceramic humidity sensors. Sens. Actuators 4, 85-96, https://doi.org/10.1016/02506874(83)85012-4 (1983).

42. Jun, L. Q., bin Djaswadi, G. W., bin Hawari, H. F. \& Zakariya, M. A. B. In 2018 International Conference on Intelligent and Advanced System (ICIAS). 1-6 (IEEE).

43. Wang, Q. H., Kalantar-Zadeh, K., Kis, A., Coleman, J. N. \& Strano, M. S. Electronics and optoelectronics of two-dimensional transition metal dichalcogenides. Nat. Nanotechnol. 7, 699-712, https://doi.org/10.1038/nnano.2012.193 (2012). 
44. Pawbake, A. S., Waykar, R. G., Late, D. J. \& Jadkar, S. R. Highly transparent wafer-scale synthesis of crystalline WS2 nanoparticle thin film for photodetector and humidity-sensing applications. ACS Appl. Mater. interfaces 8, 3359-3365, https://doi.org/10.1021/ acsami.5b11325 (2016).

45. Van Gerwen, P. et al. Nanoscaled interdigitated electrode arrays for biochemical sensors. Sens. Actuators B: Chem. 49, 73-80, https:// doi.org/10.1016/S0925-4005(98)00128-2 (1998).

46. Dastider, S. G., Barizuddin, S., Dweik, M. \& Almasri, M. A micromachined impedance biosensor for accurate and rapid detection of E. coli O157: H7. RSC Adv. 3, 26297-26306, https://doi.org/10.1039/C3RA44724C (2013).

47. Laursen, A. B., Kegnæs, S., Dahl, S. \& Chorkendorff, I. Molybdenum sulfides-efficient and viable materials for electro-and photoelectrocatalytic hydrogen evolution. Energy Environ. Sci. 5, 5577-5591, https://doi.org/10.1039/C2EE02618J (2012).

48. Nørskov, J. K. et al. Trends in the exchange current for hydrogen evolution. J. Electrochem. Soc. 152, J23-J26, https://doi. org/10.1149/1.1856988 (2005).

49. Bakhoum, E. G. \& Cheng, M. H. High-accuracy miniature dew point sensor and instrument. IEEE Sens. J. 15, 1482-1488, https:// doi.org/10.1109/JSEN.2014.2364187 (2014).

50. Fenner, R. \& Zdankiewicz, E. Micromachined water vapor sensors: a review of sensing technologies. IEEE Sens. J. 1, 309-317, https://doi.org/10.1109/7361.983470 (2001).

51. Kumar, L., Islam, T. \& Mukhopadhyay, S. Sensitivity enhancement of a PPM level capacitive moisture sensor. Electronics 6, 41, https://doi.org/10.3390/electronics6020041 (2017).

52. Feng, Z.-s, Chen, X.-J., Chen, J.-j \& Hu, J. A novel humidity sensor based on alumina nanowire films. J. Phys. D: Appl. Phys. 45, 225305, https://doi.org/10.1088/0022-3727/45/22/225305 (2012).

53. Hassan, G., Bae, J., Lee, C. H. \& Hassan, A. Wide range and stable ink-jet printed humidity sensor based on graphene and zinc oxide nanocomposite. J. Mater. Science: Mater. Electron. 29, 5806-5813, https://doi.org/10.1007/s10854-018-8552-z (2018).

54. Sajid, M. et al. Bio-compatible organic humidity sensor transferred to arbitrary surfaces fabricated using single-cell-thick onion membrane as both the substrate and sensing layer. Sci. Rep. 6, 30065, https://doi.org/10.1038/srep30065 (2016).

55. Khan, M. U., Hassan, G. \& Bae, J. Bio-compatible organic humidity sensor based on natural inner egg shell membrane with multilayer crosslinked fiber structure. Sci. Rep. 9, 5824, https://doi.org/10.1038/s41598-019-42337-0 (2019).

56. Du, B. et al. MoS2-based all-fiber humidity sensor for monitoring human breath with fast response and recovery. Sens. Actuators B: Chem. 251, 180-184, https://doi.org/10.1016/j.snb.2017.04.193 (2017).

57. Feng, J. et al. Giant moisture responsiveness of VS2 ultrathin nanosheets for novel touchless positioning interface. Adv. Mater. 24, 1969-1974, https://doi.org/10.1002/adma.201104681 (2012).

58. Jha, R. K. \& Guha, P. K. Liquid exfoliated pristine WS2 nanosheets for ultrasensitive and highly stable chemiresistive humidity sensors. Nanotechnology 27, 475503, https://doi.org/10.1088/0957-4484/27/47/475503 (2016).

59. He, P. et al. Fully printed high performance humidity sensors based on two-dimensional materials. Nanoscale 10, 5599-5606, https:// doi.org/10.1039/C7NR08115D (2018).

60. Fleming, S. et al. Normal ranges of heart rate and respiratory rate in children from birth to 18 years of age: a systematic review of observational studies. Lancet 377, 1011-1018, https://doi.org/10.1016/S0140-6736(10)62226-X (2011).

\section{Acknowledgements}

The National Research Foundation of Korea (NRF) grant funded by the Korean government (MSIP) (2019R1H1A2086726 and 2020R1A2C1011433), and Jeju Sea Grant College Program funded by the Ministry of Oceans and Fisheries supported this work.

\section{Author contributions}

M.A. and M.U.K. are first authors as equal proportion. M.A. and T.E.C. designed and performed the simulation measurements and performed the mathematical modelling. M.U.K. designed the experiment, fabricated the sensor, and recorded the practical measurements. T.E.C., M.U.K., M.A., A.H. and J.B. analysed the measured data, prepared the manuscript, and discussed the results. A.H. and J.B. supervised the research.

\section{Competing interests}

The authors declare no competing interests.

\section{Additional information}

Supplementary information is available for this paper at https://doi.org/10.1038/s41598-020-62397-x.

Correspondence and requests for materials should be addressed to A.H. or J.B.

Reprints and permissions information is available at www.nature.com/reprints.

Publisher's note Springer Nature remains neutral with regard to jurisdictional claims in published maps and institutional affiliations.

Open Access This article is licensed under a Creative Commons Attribution 4.0 International License, which permits use, sharing, adaptation, distribution and reproduction in any medium or format, as long as you give appropriate credit to the original author(s) and the source, provide a link to the Creative Commons license, and indicate if changes were made. The images or other third party material in this article are included in the article's Creative Commons license, unless indicated otherwise in a credit line to the material. If material is not included in the article's Creative Commons license and your intended use is not permitted by statutory regulation or exceeds the permitted use, you will need to obtain permission directly from the copyright holder. To view a copy of this license, visit http://creativecommons.org/licenses/by/4.0/.

(c) The Author(s) 2020 